\title{
The Art of Writing Social Sciences: Disrupting the Current Politics of Style
}

\author{
PARISs Collective* \\ parisseditorial@gmail.com
}

\begin{abstract}
Through a critical engagement with substantive and stylistic guidelines dictated by dominant journals in the social sciences, this article enquires on what it means to write like a social scientist in the twenty-first century. Academic production and diffusion now regularly take place beyond and across national borders, with English often standing in as the lingua franca of these global exchanges. Though just one effect of this restructuration, academic journals have become more transnational in scope with regards to the authors whose work they publish and the audiences whose readership they seek to attract. However, while one could expect the "globalization" of the social sciences to lead to the transnational circulation of national disciplinary traditions and perhaps multiple manifestations of cultural hybridization, we are instead witnessing the imposition of a strangely singular and harmonized mode of doing the social sciences. Paradoxically, standards of how long a scientific article should be or how one should fashion an argument are so familiar and intimately known, yet curiously opaque and of unknown origins. In interrogating the historical-contextual origins of conventions that so strongly shape the world of academic publishing and, dare we say, reasoning, we raise questions about the conditions of the present and the naturalization of standards on how to write a scientific article. As a consequence of
\end{abstract}

* Monique J. Beerli (Université Libre de Bruxelles-RePI and Sciences Po Paris - CERI); Emma Mc Cluskey (Department of War Studies, King's College London); Didier Bigo (Department of War Studies King's College London; Sciences-Po Paris-CE RI, France; Director of the Centre d' etudes sur les Conflits, la Liberté, la Sécurité (CCLS)); Tugba Basaran (University of Cambridge).

This order of authors was chosen randomly, throwing a dice, to emphasize the true collective nature of the article's authorship. 
this exploration, we propose alternatives guidelines that a new journal such as ours has to present to its anticipated authors and readers.

\section{Keywords}

social sciences - politics of style - collective - reflexivity - writing - transdisciplinarity

\section{A Politics of Style}

The art of writing social sciences has many embodiments depending on the disciplines' trajectories, the national traditions of philosophy, rhetoric, and literary expressions. ${ }^{1}$ This diversity is the proof that no language or style can pretend to be the best rationale and the voice of logic. Nevertheless, main journals and even some research agencies have disciplined the art of writing by enacting specific rules that impose a certain politics of style. This contribution will discuss some of the taken-for-granted rules of writing a scientific article as a particular textual genre, such as the necessity to have one main argument, to have single-authored pieces, to write 8 to 10,000 words, to present the research in a particular outline, as a demonstration of the theoretical approach via case studies, to repeat findings in the conclusion, and so forth. These "rules" have come to structure the imposition of a legitimate mode of doing and writing social sciences (problématique légitime). We will establish our critique of these stylistic rules by showing their inner politics, thereby challenging the seemingly innocuous nature of stylistic guidelines that journals recommend and some writers give in to. Additionally, we will address forms of discrimination produced by and through journal rejections, which are not exclusively representative of the quality of an article, or merit based, but also of a specific game played by reviewers. It is thereby through this inquiry into the rules about the "art of writing" and a reflexive stance towards our role as editors confronted with articles evaluated through a process of peer review that we are accentuating the urgent need to politicize styles of writing and producing academic knowledge. Thus, our strategy for taking issue with the politics of style now dominant in the (written) world of the social sciences is to reveal forms of arbitrariness at the heart of everyday decisions to publish or not to publish.

1 Anna Dusak, ed., Culture and Styles of Academic Discourse (Berlin: De Gruyter, 1997). 
Our choice to open the first issue of PARISS with a conversation about the politics of style comes from collective discussions ${ }^{2}$ and a reflexive attitude towards the implications of publication decisions emanating from editors' and publishers' guidelines as well as rules for readers and reviewers. In extending a conversation initiated by others and positioned as the starting point of PARISS, we aim to facilitate transdisciplinary ways of writing. We envision pluralization as key to contesting the symbolic violence of prescriptive rules of style currently so prevalent in the dominant so-called "global" social sciences system. ${ }^{3}$ But before even being able to think seriously about alternative ways of writing or, more generally, communicating 'like a social scientist,' an epistemological break must first interrogate the standards of evaluation, valuation, and judgement that have become so important to the academic field. To illuminate the logics and forces underpinning contemporary measures of 'good scholarship,' we propose a return to and an extension of the strides made most fervently by historians, philosophers, and sociologists of science in their multiple quests to 'exoticize the domestic' 4 and seize the uneven effects of domination produced by the formation of disciplines ${ }^{5}$ and the internationalization of the social sciences. ${ }^{6}$ More precisely, we endeavor to think reflexively and collectively about academic writing and, more specifically, the journal article as a particular communicative form. Our technique is thus to pay heed to the politics of style defining what it means to be and write like 'a (social) scientist' so as to render visible dominant modes of evaluating scientific production and the effects they generate. This disruptive exercise might appear masochist to some, particularly those who might be at a loss in daring to no longer be complicit in defending the universality, neutrality, and objectivity of the presently dominant measures of 'scientific quality.' Our diagnostic, however, is of a more optimistic leaning, that in offering a space (not a directive) for scholars to challenge convention and exercise creativity, the 'art' of scholarly production may be reinvented. Without the pretension of fully dismantling the current order of things, PARISS nonetheless aspires to foster the blossoming of a more pluriversal and heterogeneous social science.

2 We thank the members of the PARISS editorial board and scientific committee who have directly contributed to this collective discussion and nourished our own reflection.

3 Michael Kuhn and Hebe Vessuri, eds., The Global Social Sciences: Under and Beyond European Universalism (New York: Columbia University Press, 2016).

4 Pierre Bourdieu, Homo Academicus, trans. Peter Collier (Palo Alto: Standford University Press, 1988), xii.

5 Immanuel Wallerstein, Open the Social Sciences: Report of the Gulbenkian Commission on the Restructuring of the Social Sciences (Palo Alto: Standford University Press, 1996); Andrew Abbott, The Chaos of Disciplines (Chicago: University of Chicago Press, 2001).

6 Michael Kuhn and Doris Weidemann, eds., Internationalization of the Social Sciences: AsiaLatin America - Middle East - Africa - Eurasia (Bielefeld: Transcript, 2010). 


\subsection{Prescriptive Rules of the 'Global' Social Sciences}

"Articles must contain an original argument. They should be between 8,ooo and 12,000 words, including the abstract, bibliography, and endnotes. Authors must respect the journal's stylistic and formatting criteria." Any seasoned academic would quickly recognize these prescriptive norms as constituting the habitual list of requirements imposed by academic journals upon prospective authors. As academics, we constantly interact with these rules, either as their enforcers or their subjects. Collectively revered as upholding the pillars of scientific rigor and reasoning, these seemingly insignificant parameters of style, structure, and demonstration compel scholars to write and produce knowledge in a particular way. More than structuring dominant modes and architectures of expression, they co-constitute the systems of appreciation, valuation, and judgement determining the 'quality' of research. From a preliminary inquiry into the guidelines of twenty major journals in the fields of sociology, anthropology, political science and international relations, ${ }^{7}$ four criteria emerge. First, argumentation and structure: articles should have one main argument structuring the reasoning; the introduction should specify the research question and explicitly outline the structure of the article; the methodology and case study should then be presented, followed by a presentation of the findings and a conclusion which synthetizes the argument. Second, clarity and demonstration: in order to be considered original and "new," the paper has to privilege a step-by-step approach with short sentences in order to deliver clarity and to be comprehensive. Third, referencing and simplicity: quotations and discussion of the literature can be reduced to a Harvard style presentation and a minimisation or absence of footnotes. Fourth, word count: the average article has to be around 8 to 10,000 words. Nearly omnipresent, these four requirements constitute minimum barriers of entry to publication. Passing off as unobtrusive and inconsequential, these rules have been structured in part by economic and social considerations that require further investigation.

\subsubsection{On Word Counts}

Poking around even a little bit exhibits an arbitrariness which is no longer relevant and whose reasoning has long been forgotten. Take for instance the issue of word count. The logic of the economy of the printing press, whereby $3^{2}$ pages of paper was considered as most cost efficient to print, cut and bind, plays no insignificant role. The rationale of producing journals composed of

7 Most notably: International Organisation, American Political Science Review, International Security, European Journal of International Relations, Security Dialogue, Review of International Studies, American Sociological Review, World Politics, European Sociological Review, Anthropological Theory, Current Anthropology. 
four lots of eight pages was, for no surprising reason, also deemed a suitable reason for designating 8,000 to 10,000 words (depending on the font) as about right to constitute a 'comprehensive' article. ${ }^{8}$ In the digital age, these regulations are of course completely immaterial and redundant, but the tradition survives. Publishers have justified this continuity in form in order to differentiate and protect the specificity of the 'social science article', which must be longer than a journalist newspaper or a blog, but short enough in order to avoid losing the interest of a reader who, supposedly, becomes easily tired and inattentive if the article is any longer.

\subsubsection{On 'Direct Style'}

The choice to privilege direct over indirect style is not a question of aesthetics, it is a question of politics of style and even cultural hegemony. ${ }^{9}$ It may work to assert an argument as a theorem but is often unable to create the conditions of possibility of reflexivity of the author on its own position, (contrary to the indirect style). The choice for a direct style de facto concerns the framing of the boundaries of social sciences and of its key modes of reasoning. Direct style, praising linearity, simplicity, clarity, speed, is profoundly connected with the structuration into one main argument and refusing the many intertwined sentences which are often necessary to explain complexity and assemblages. Direct style and the will to develop a research question via only one argument are also structured to justify a certain vision of social science as centrally quantitative, building an alliance with mathematics and physics, and rejecting humanities as inconsistent forms of knowledge production. This led to a rational choice theory position and the belief that a demonstration is possible in social sciences and that authors may discover laws. A relational and processual approach inclines to the contrary. This second option will consider that theorising is not a generalisation via inferences towards an abstraction to find in Plato's cave, but is a reflexive practice over the practices of human beings in a certain place and time. It is about observing relations, process, dynamics of social and political lives, taking into account their historicity and singularities, whilst recognizing that contingency is never pure hazard. Obviously, style by being direct or indirect favours a certain approach, essentialist or processual,

8 Ronald Deibert, Parchment, Printing, and Hypermedia: Communication and World Order Transformation (New York: Columbia University Press, 200o).

9 Kazumi Okamoto, "Internationalization of Japanese Social Sciences: Importing and Exporting Social Science Knowledge," in Internationalization of the Social Sciences: Asia - Latin America - Middle East-Africa-Eurasia, ed. Michael Kuhn and Doris Weidemann (Bielefeld: Transcript, 2010), 58 . 
and, as developed by Yosef Lapid in the seminal introduction of the book on Identity, Borders and Orders, is never innocent in its ontological and epistemological dimensions. ${ }^{10}$ An essentialist approach privileging a single argument will use a long list of names and few verbs while a processual philosophy will do the contrary and will often create words to have more verbs and fewer names in order to render the dynamics of practices into the language.

\subsubsection{On the 'One Argument' Rule of the Essay Style}

The most familiar and strongly problematic requirement for writing like a social scientist is to adhere to the rule of one key argument throughout the article. The argument should be clearly stated in the abstract, again in the introduction, referred back to at numerous points throughout the main body of the paper, and then repeated again in the conclusion. A long tradition in the Anglo-American world of writing an 'essay' has crystallized into absolute rules learnt from school: to have an overarching argument, repeated all along the paper to show the coherence of the thought, a bit like an exo-skeleton, strong and highly visible. It creates for many readers the frequent impression of repetition more than progression and often discourages reading the different parts in order to jump to the conclusion. When it is well done, it gives a performative sense of success of a demonstration, to have real progress in the reasoning, to obtain an explanation and not just an interpretation. It is 'convincing' and mimics hard sciences. This is certainly one of the main reasons for its wide success, including amongst the non-Anglophones. This is why the scholarly articles of so many journals take de facto the form of an essay, framed through a research question, in need to be answered with a series of deductive parts (four, five or six) connecting the theoretical question to different case studies, considered as a series of means to test the 'real' in order to demonstrate the validity of the answer and more precisely a percentage of truth and error. The arbitrariness of the art of writing in a certain group of disciplines, called the social sciences, seeking to distinguish themselves from the humanities and 'hard sciences', are rarely discussed. The essay style with its one argument rule looks so 'natural' that nobody contests this way of arguing. It has become common sense. Social sciences articles have to be presented under these rules, considered as neutral and purely formal. But, is it the case?

10 Mathias Albert, David Jacobson, and Yosef Lapid, Identities, Borders, Orders: Rethinking International Relations Theory, Borderlines, (Minneapolis: University of Minnesota Press, 2001). 


\subsubsection{The Arbitrariness of Conventions}

Sociolinguists and linguistic anthropologists would perhaps label these practices a 'language ideology'll or 'academic discourse', ${ }^{12}$ which resonates with what we call here a 'politics of style'. The sociologically inclined would emphasize the structural impact of submission guidelines in structuring hierarchies within academia as a professional field, ${ }^{13}$ offering a lens into the forms of classification created by and used as mechanisms of judgement and ordering. Professors in composition and rhetoric insist on how stylistic traditions are embedded into rhetorical strategies and ideas of the sciences that are temporally situated, and which are often obsolete in the domain it emerges, but still in fashion in faraway domains. They insist that a specific art of writing imposes a politics of style which has initially implied the deployment of rhetorical resources, in written discourse, to create and express meaning, but which becomes routine and disappears as a style to become just a way of writing, leaving behind its own original fights. The grammar of style-understood as the set of conventions governing the construction of a whole composition-becomes invisible and is reproduced without thinking. Technicalities of the digital age, such as the type of file or the preferred bibliographic style, are often the only guidelines journals explicitly expound, but the politics of reproducing a certain style valorising short sentences and straightforward terminologies in the name of clarity, comprehension for a large public, and simplicity is the same politics that insists on the necessity of writing an 'essay' article, that prefers a minimalist aesthetic of one central argument carried throughout the entire paper, and that pretends a paper has to demonstrate the added value of its conclusions and its radical novelty for it to be of any worth. In many journals, this stylistic predilection strides side by side with a preference for quantitative data and an instance on the reproducibility of results

According to this mode of reasoning and system of valuation, the so-called 'bad papers', that is the rejected ones, therefore, are the opposite. They are short papers of less than 8,000 words or long papers of more than 12,000 words, with lengthy sentences that develop complex ideas that are best kept together instead of being broken down into parts, thereby requiring the reader's attention. Worse still, they do not conclude with a solution to a problem, as

11 Jan Blommaert, ed., Language Ideological Debates, vol. 2 (Berlin \& New York: de Gruyter, 1999).

12 Dusak, Culture and Styles of Academic Discourse.

13 For a piece on how this plays out in the field of international relations, see Ole Waever, "The Sociology of a Not So International Discipline: American and European Developments in International Relations," International Organization 52, no. 4 (1998). 
such. Rather, they are profoundly dialectical or even a resolutely heterogeneous collage obliging the reader to actively ponder what the conclusions could be. The critiques by reviewers are standardized: these papers are bad because they do not really develop abstractions, do not consolidate and build a future knowledge ... and therefore are not publishable. But this type of rejection is more often than not an opposition to any deviation from 'essay rules', an easy way to discriminate against other languages, styles, rules of enunciation, or just a hidden opposition to the content without a serious intellectual argument.

The current aesthetics of style of a certain English language privileged mainly by US social sciences cannot escape the questions on its impact as a norm, marginalising other ways of writing, associated with location in the world, past colonies, gendered grammars and class locutions.

\subsubsection{Enquiry into the Current Rules of Writing Social Sciences and \\ Experiences of Peer Review Systems: A Politics with no Name?}

As we said, this position to reflect on the practices of editorial guidelines is not just an enthusiasm for a new formula, it comes from a long period of dissatisfaction with the current publishing world in social sciences and its form of hegemonic autopoiesis. The belief that one can exist as unique, but universal, and compulsory for social sciences in general, has certainly played a role in the illusio of a manifest destiny superior to the other nations and a distance towards the tendency in other countries to develop a discourse of shared destiny and a belief that the world is richer by its diversity. Journals in the US (and anglophone world) have seen themselves as the unique vector of the universal, and have recognised recently the competition from the Chinese publishing industry only to unanimously reject it as an illegitimate competitor for expressing global knowledge. Therefore the rules they have put in place for writing and reviewing are born under the double patronage of practical reason, with an effort of depatronising existing journals by constructing peer reviews and quality assessment, while keeping the style as a non-democratic question, as one pertaining only to the Anglophone specialists. For reviewers, this has created easy ways of discrediting papers from other countries in the name of their errors in English, by pointing to their styles of argumentation even when grammatically they are perfectly correct. Before developing this point however, we have to understand better what are the so-called common rules of today's social sciences publications in English. We will not propose a systematic analysis, we simply want to open the journal with some provocative questions, but we welcome with wide open arms numerous and diverse papers on this topic of politics of style and its exclusionary or inclusionary effects. 
For the moment, if we synthesized briefly the current guidelines or recommendations before sending an article to a journal of English social sciences, which most journals will call rules, we find a series of common characteristics, which are more explicit in some journals than others, but which are considered as the evidence that any new writer needs to know.

Among the journals the most quoted in sociology, political sciences and international relations, International Organisation gives a full measure of its quality requirement. In what they call diction, they insist: "Offer your readers vigorous, concise prose in the active voice. Choose vivid verbs and expressions that clearly communicate your meaning. Avoid using academic, 'insider' jargon". And they clarify in the economy of writing: "Weak and extraneous prose detract from the strength of your argument. Scrutinize your draft for potential deletions, such as expressions, sentences, and paragraphs whose absence would not harm the argument or would help it to stand out more prominently. Prime candidates are complex constructions where simpler phrasing would do, distractions from the main line of argument, and excessive repetition. Rare is the manuscript that cannot be improved with tightening. The following classics offer much concrete advice: The Elements of Style by William Strunk and E. B. White, On Writing Well by William Zinsser and The Careful Writer by Theodore M. Bernstein."14

For those who managed to escape these standards in high school or their first year of university, it is necessary to remember that The Elements of Style is an American English writing style guide with numerous editions. The original was composed by William Strunk Jr. in 1918, and published by Harcourt in $1920 .{ }^{15} \mathrm{E}$. B. White greatly enlarged and revised the book for publication by Macmillan in 1959. That was the first edition of the so-called Strunk \& White, which Time named in 2011 as one of the 100 best and most influential books written in English since 1923. It is based on a triple credo of what is a good English style: 1) Omit needless words. 2) Use active voice. 3) Use parallel construction on concepts that are parallel. After the death of Strunk in 1946, White continued alone the third edition of 1959, and developed a forty-three-page summary of "the case for cleanliness, accuracy, and brevity in the use of English". ${ }^{16}$ The three editions together were sold in more than ten million exemplars. A tradition of writing English that the great writer Spencer would not have recognised with its magnificent long sentences will take over and will

\footnotetext{
14 Theodore Menline Bernstein, The Careful Writer: A Modern Guide to English Usage (New York: The Free Press, 1965).

15 William Jr. Strunk, The Elements of Style (San Diego: Harcourt, 1920).

16 William Jr. Strunk, The Elements of Style, 2nd ed. (New York: Macmillan, 1959).
} 
continue to be praised by most journals of social sciences, especially in the US. First subtitled as an "informal guide" and then "the classic guide," On Writing Well by William Zinsser, ${ }^{17}$ also recommended by International Organization, was the new enforcer of the same dogma. ${ }^{18}$ As a journalist from the Herald Tribune and teaching later at the New School in New York, he insisted that short sentences were better, they added clarity and they helped to understand an argument. He clearly considered that journalists could be a model for social scientists, who were often too "obscure".

George Orwell in his famous essay 'Politics and the English language' was not in disagreement with this way of presenting an art of writing based on simplification and clarification, against complexity and the invention of specific words, which were pejoratively termed 'jargon' if lay people could not understand them. ${ }^{19} \mathrm{He}$ insisted that political language as such was often based on vagueness and insincerity and that against them, engaged journalists had to speak plainly to a large audience and had a specific responsibility for developing education and socialism.

He considered that it was crucial to oblige academics to go outside of their so-called ivory tower and to meet the "real people". He was harsh with the English intellectual "elite" and their "convoluted" speeches, considering that this group was influenced by German and French ways of thinking. His critic of the communist bureaucratic jargon adopted by the English upper class to control the proletariat in the novel 1984 was by far more central than the interpretation of his novel as a tale against totalitarian regimes or technologies of surveillance. It was a way to attack both the simplistic populist discourses and propaganda playing with primary emotions and the technical control of language by a bureaucracy willing to control through a language without nuances, the possibility to express resistance, to continue to have memory and archives allowing traces of objective facts. At the same moment, was he not himself criticizing the journalist's willingness to reach the people and to speak not in their name, but instead of them? It seems so. He knew his politics of style leaning towards simplification, clarity and straightforward reasoning to speak to the people had to have limitations and that the work of the journalist was not that of researchers. He did not really engage with this tension between the two professions and privileged the goal of speaking for all over its dangers in his nonfiction papers.

17 Zinsser was born in 1922 and died in 2015.

18 William Zinsser, On Writing Well: An Informal Guide to Writing Nonfiction (New York: Harber \& Row, 1976); William Zinsser, On Writing Well: The Classic Guide to Writing Nonfiction, 9 ed. (New York: HarperCollins, 2006).

19 George Orwell, "Politics and the English Language," Horizon 13, no. 76 (1946). 
As we see this conjunction of traditional and socialist arguments in favour of a style based on the clarity of a reasoning which has to demonstrate the validity of an argument by inferring from a specific moment a more general truth, has important implications on the practices of doing research until today. It implied a certain idea of social science, as a science for the people, and it positioned social sciences at a distance from humanities and in a mimicking position towards the so-called "hard" sciences.

\section{The Triumph of Social Sciences as Specialized Journalism in the Need to Make Profit}

From all sides, the idea that social scientists were first and foremost artists of creating new ideas with new words, and that their role was almost entirely in this performance, was defeated. Social scientists had to speak and write to convince large audiences, not a small group of peers. They had to rely on their capacities to make money on a larger publishing market, not as university professors paid by the state. It seems that it is still the case with the 'publish or perish logic', the multiplication of self-plagiarism to add the numbers of papers produced in order to please different audiences, and often the adjustment of the text to the idiosyncratic preferred journal's authors. The number of words for an article, beyond the hysteresis of attitude coming from a pre-digital era implying economic choices, is often based on estimates of the capacity of the supposed audience to read carefully and not on the degree of precision of the meaning and its goldsmith quality. This relation to an audience, perceived as poorly specialized, is crucial in understanding the current rules of writing with one simple argument which is operating as a justification to continue the practices of the past and its dominant legacy. Digitization has also reinforced partly this idea to write in clear and simple terms for different audiences, and by multiplying "blogs" and even tweets. The idea to influence opinion by way of writing social sciences was not at all a linear destiny connected with the progress of technologies of communication. It has been a certain turn that social scientists have developed in relation to their enrolment into propaganda, very quickly renamed for some public relations and, nowadays, strategic communication. The turn of the Second World War was significant, and it continued after wards with the Cold War. Psychology and journalism studies reinforced the trend towards simplification of thoughts and words. Continental philosophers, structuralist sociologists and anthropologists were obliged to struggle and to adapt to the trend if they still wanted to publish and not to be considered as "obscure". 
One key moment of the success of the politics of an essay with one straightforward argument that can be easily read came when the disciplines of social sciences were confronted with the development of humanities and their challenge concerning forms of knowledge. The 1970s have been the golden age of this "art" of writing where the US social sciences imposed their hegemony on style at the very same moment that they won the war on dictionaries and imposed by default their spelling, before opening up again to a multiplicity of other English languages, including the English one as a variable. The success will nevertheless be short. This sense to have a linear demonstration where every step is precisely described, which was at the foundations of the argument of a social science essay was put in question at the moment of its climax by the evolution of both the hard sciences, the cybernetic and the "nouveau roman" all together.

The so-called French theory, post structuralist, nouveau roman, constructionist approaches of language attacked these ideas of linearity and simplicity, the idea of reason as universal and insisted on situated forms of knowledge having no access to an "aleph", a local point giving access to the universal to paraphrase Borges. ${ }^{20}$ They refused, for some of them, the character of science to social scientists and destabilized their claim to authoritative knowledge based on fact.

Be they Nietzschean or Libertarian, they proposed to disrupt the pretence of science, in interpreting social activities. They rejected the ideas of inference, generalisation, explanation, and especially the idea to do that through quantitative methods and behavioural techniques constructing statistical generalization leading to prediction. They considered that the practice of imposing a scientific style based on the belief to be an explanation, with inferences toward the abstract generalisation and ultimately the universal, was a form of academic hubris coming from dominant white male positions inside the university and reproducing a certain type of presentation of research design via the triptych: theory, methods and cases studies, which had to be taken for what it was: a hegemony by an elite (Ivy league in the US, Russel Group in the UK) in danger to lose their dogmatic positions of authority and reacting by a war on scientific publications imposing a unique path to knowledge.

The controversy of quantitative versus qualitative methods which was so important in the late seventies and eighties, was therefore settled momentarily to save social sciences from this "invasion of barbarians" and social scientists, historians, political theorists coming from the European continent. A wall was erected between disciplines and in many campuses, social sciences left 
humanities departments to escape the contamination, joining new branches of "sciences": media studies and informatics. The French and continental theories of social sciences were confined easily to the German and French language departments of US and UK universities. It was the same for the critiques coming from Latin America which were examined in the Spanish department as "novels".

A key book, organizing this "division of labor" and methods between social sciences and the French theories colonizing language department but also their neighbours, history, philosophy is Designing Social Inquiry: Scientific Inference in qualitative research written by Gary King, Robert O. Keohane and Sidney Verba. ${ }^{21}$ The book organized the reconciliation between different tendencies of research design and the tension between the quantitative turn of departments of politics, IR, general sociology versus anthropologists and historians often fighting for a more qualitative, interpretive approach, based on nuances, the absence of over-generalization, even if famous "traitors" existed in both camps. Still considered today as an absolute requirement, at least in political sciences and IR, the core terminology chosen to create a boundary between social science and other narratives was "inference".

Social sciences are straightforward and reason in a quasi-mathematical way by advancing an argument step by step in a clear way, and by proposing a reproducible model where what they say on a case can be repeated in other places by other social scientists. For them comparison is reason through abstraction and de-personalisation of the researcher whose ethos and emotions as well as political values could not be taken into considerations. Theory is conceived, not as the result of the research of specific human practices, but as the opposite of the "empirical", and its goal is access to a pure knowledge, in the most abstract way, almost a mathematics of forms (based on an aesthetical geometry of symmetries, balancing dual poles) detached from any content and therefore reproducible anywhere. The frequent result of the essay-article is therefore to tend to confuse abstraction, concept and theory. It embodied into the style an ontology distinguishing theory, methods and case studies as three categories allowing to purify from the empirical as matter, the abstract as the essence of knowledge, its spirit. Quantitative and qualitative methods may be used but only if they are based on inference as the intellectual mechanism linking simplicity of style with step by step argumentation in favour of a demonstration in the conclusion. The triumph of the essay as the way to write a

21 Gary King, Robert O. Keohane, and Sidney Verba, Designing Social Inquiry: Scientific Inference in Qualitative Research (Princeton: Princeton University Press, 1994). 
social science article was preserved by the consensus on the necessary "design" to be labelled "social science".

Like wrecking balls threatening the structural integrity of a building with each moving swing, streams of critical theory and postmodernist thought have assailed the assertive position of a positivist epistemology within the social sciences. This offensive has undoubtedly had varied results across time and space, across disciplines and institutions, producing a complex intellectual terrain whose topography is the product of ongoing shifts. Nonetheless, from a bird's-eye view, it would seem that 'anti-positivist' approaches, if lumped together, have victoriously carved a space for themselves within the humanities and social sciences with the late nineties and the American touch reinventing beyond recognition French theorists and postcolonial writers radicalizing the critiques. The specializations of faculty now found in institutions of higher education, the pluralism of teaching curricula, and the existence of academic journals open to or even dedicated exclusively to critical theory all speak to ruptures that have been made with traditional conceptions of science, reason, and method. Have we therefore a reversal of positions in social sciences? Are styles now a question of choice? Is it not a Pyrrhic victory? Homo Academicus: A Sticky Practice of Style Despite Challenges

If we analyse today adequation between the style of social sciences journals and what they say of their ontologies and epistemologies or methods, it seems that the "critical" journals are less critical than they think. The style of the one argument fits certainly with a Newtonian world of calculus and almost certainty but is much more problematic to express constructionist approaches and post-structural forms of reflexivity insisting on the work done by the use of style itself. So, how can we embark towards a different art of writing? How can we disrupt the logic of one argument and propose a new ethos for writing social sciences? Do we have to reinvent everything or could we base our judgement on other traditions, for example the "Latin" ones concerning dissertation structures as the best way to write articles in social sciences?

\section{1}

Pluralising the Art of Writing Social Sciences

Obviously, writing a social science article is not necessarily following the essay style. This style may be hegemonic today but, in fact, is isolated at the world level, and goes de facto against many other traditions, especially the one of the dissertation. In the dissertation style of article, almost everything contradicts 
the recommendations of the good essay article. The introduction has to situate the "disputatio" between scholars, to present their respective positions, the reasons of their oppositions and it is only after this presentation than one dare to risk to introduce a question, which is not a scalpel towards the real, but more often a way to reconcile or disrupt the previous arguments which were previously in favour. In addition, often based on a more dialectical understanding of the progress of reasoning, and of an insistence of the conditions of productions of the debate in a certain place at a certain time, the formal standpoints of the dissertation are more on a formal structuration of two or three parts maximum, after a long introduction, sometimes occupying a third of the paper, situating first the thought of the others before claiming any originality, and finishing the article with a bolder statement by a new set of questions, opening the space of thought for future research. It is worth noticing that the conclusion is never the repetition of the argument as it would be insulting the capacity of the reader, but a new question which has emerged along the reasoning. The conclusion is therefore an attempt to generalize inductively. While significant distinctions between ways of writing a dissertation exist, this approach to writing an article is by far more common in Germany, France, Spain, Italy, Portugal and of course this binary distinction between the essay and the dissertation does not account for many other cultural and stylistic traditions with their own formats and politics of style.

People trained to write dissertations, feel often that they are obliged to cut nuances, to destroy the dialectical moves of presenting both faces of the pro and contra and to assume from the beginning a clear statement masked as if it was a question, but often already a result. The one argument may appear not as clear, simple and therefore accessible to a large audience, but as an oversimplification, creating a false hierarchy between criteria depending on the focus chosen by the analyst. They may also consider that a proper reasoning implies always a chain of arguments that are intertwined in mutually constitutive relations, and that a stylistic presentation around one argument subsuming the others, even if it is the one of complexity, cannot escape the linearity of the step by step reasoning.

In "out of style" Paul Butler has rehabilitated obscurity as a way of obliging the reader to think, to question in order to challenge both the essay and the dissertation styles. ${ }^{22}$ Promotors of alternative styles have experimented common strategies with artists, novelists and created many hybridizations in the art of writing, of communicating with multiple formats (text, audio, videos)

22 Paul Butler, Out of Style: Reanimating Stylistic Study in Composition and Rhetoric (Logan: Utah State University Press, 2008). 
and they have developed what has been named "patchworks" or "collages" in social sciences. Latin American authors have often considered, in social sciences and especially to describe mobility of people, travels, trajectories of life, that they had the licence to construct their argument in a way which was in convergence with their literature and that the use of metaphors and analogies was a tool for the reasoning as scientific, and a better one, than the para-logic of a pseudo mathematical reasoning. ${ }^{23}$

In a world where English becomes the vernacular language for many other writers who have English neither as a mother tongue nor as a practice of the essay as a scholarly exercise, this creates a sense of estrangement, surprise, sometimes pleasure, but often unease to write an article with one argument only in a straightforward way of analysing practices. The pleasure of discovery goes hand in hand with this estrangement to discover another "self" when writing along these rules that many feminists consider as manly structured by their aggressive direct style. Equally battling against the subjective/objective dichotomy in conventional understandings of how knowledge is produced, feminist scholars have argued for and show us more transversal paths, strolling, in the narration. ${ }^{24}$ This more narrative style is of course possible with the English language, but it has been almost banned from the way of writing a social science article. One of the goals of PARISS is to use this flourishing style that English novels, before Hemingway, succeed to do, to creolise them with new strategies of writing and to see if it ultimately rehumanizes social sciences. A great deal of work is still to be done.

Despite all these promises, in the 2020s, we have to admit that the one argument type of essay to write a scholarly article continues to be largely dominant

23 Michael J. Shapiro, "Metaphor in the Philosophy of the Social Sciences," Cultural Critique, no. 2 (1985).

24 Cynthia Enloe, Bananas, Beaches and Bases: Making Feminist Sense of International Relations (London: Pandora, 1989); Christine Sylvester, Feminist Theory and International Relations in a Postmodern Era, Vol. 32 (Cambridge University Press, 1994); Katharine HS Moon, Sex Among Allies: Military Prostitution in US-Korea Relations (Columbia University Press, 1997); Lily HM Ling, Postcolonial International Relations: Conquest and Desire between Asia and the West (Palgrave, 2002); Veena Das, Life and Words: Violence and the Descent into the Ordinary (Univ of California Press, 2006); Tami Coby, "From the Trenches: Dilemmas of Feminist IR Fieldwork." In Feminist Methodologies for International Relations, ed. Brooke A. Ackerly, Jacqui True and Maria Stern (Cambridge: Cambridge University Press, 2006), 153-73; Erin Baines, Buried in the Heart: Women, Complex Victimhood and the War in Northern Uganda (Cambridge University Press, 2017); Paulo Ravecca and Elizabeth Dauphinee, "Narrative and the Possibilities for Scholarship," International Political Sociology 12 , no. 2 (2018): 125-38. 
and that this style is still the matrix for judgement. Evaluators judge along these criteria coming from the very same tradition of inference and "minimalism" embedding into its "design" an imaginary world of scientificity of the social, based on the so-called capacity, or not, of the author to generate a "concept" that can be applied to read the real in its different manifestations, and will be supposedly tested or refined after a series of iterations. The long discussion of the conditions of possibility of the emergence of a situated practice, so important for other traditions more oriented towards historical sensibility, are still often dismissed and asked to be reduced in the article (when they exist) while the willingness to engage philosophically in an "abstract" conversation with a research question based on a concept is still considered an "advance" of science. Some journals which are critical in terms of episteme and innovative in terms of methods continue to be strongly reactionary when it comes to the art of writing, and they create disjunctions between talking about innovation and doing it. In fact, it is really surprising to see how many contemporary journals of social sciences, claiming they work for "emancipation", are nevertheless among the first to duplicate the "essay" rules, the argument of clarity and simplicity for their audience, and they continue to generate for their authors guidelines reproducing a social scientist point of view closer to the late nineteenth century than the beginning of the twenty-first century.

This lack of reflexivity, is maybe inherited now from a habitus where a certain kind of training in higher education in the UK, constructs the current type of essay style as a normalcy by excellence. While the discourse of opening to "the global" is on the rise in many anglophone universities, training about the right style in English is increasingly a requirement and not a recommendation, and is assorted with sanctions if not respected, either for publication or for grants.

In line with a certain administrative style, this politics coerces creativity, even when it pretends to open curriculum to other cultures and genders. The style functions as an assimilationist move giving priority to the locutors whose mother tongue is English, while pretending to pluralize the content. It becomes laughable and sometimes caricatural, when the valorisation of a nonanglophone author is done only through the very small part of their work that has been translated and without any original piece quoted. This, of course, limits reflexivity about the use of language and its connection with a certain frame of the world, which is co-constitutive of a certain disciplinary approach in a certain culture. The prejudice enacted by the belief of a universal social science language in English extracting from other languages their "best" works is not diminishing; on the contrary it rises in this period led by a "publish and 
perish" individualisation of quick but numerous articles allowing only one dominant and vernacular language to be known, with no verification of the quality of translation.

This also turns into a comparative advantage when the matrix of "impact factors" for quotation reproduces this prevalence of one language. But this imposition of a style and framing of thought, debasing the other ways to express ideas in social sciences, is easily forgotten, especially for those who benefit, by the eschatological vision of speaking to the maximum of people, in a global world, and to attend to the privilege of the universal through the English language. It is not always strategised as such, they just forget that their aesthetic of the English language as designed for social sciences is shared between them but is not universal. It comes only from a monopoly on their part to claim that the English style they chose is "the" universal, the "mathematics" of communication in social sciences, because they own the structural positions to say that in the most saleable journals. If something is not written in English, it doesn't exist in the academic world. We may even concede to them that their aesthetics is "true", but only as a "phenomenology of the aesthetic experience of those who, in Bourdieusian terms, "are the product of school, leisure, distance from economic necessity, and practical urgency" and, we have to add, who also have been educated in English. ${ }^{25}$ To know this leads to a cultural politics which is opposed both to the absolutism of the knights of culture constituted as the preserve of the league of a few happy universities and journals, and to the program of universalizing through a strategy of assimilation; a strategy which is not reflexive about the corridors they control and the place they occupy as gate keepers by continuing to propose a review process exclusively in English. As we will see, it is almost impossible to fully escape this position when publishing a social sciences journal, but some reflexivity allows amendments regarding the politics of style, the mechanisms of the review process and the submission of manuscripts in different mother tongues, the choice of the reviewers and the ambiguities of anonymity, as well as the politics of translation, not only of language but also of dealing with the "untranslatable".

\section{The Art of Writing Social Sciences Reflexively: Alternatives to Apply for PARISS}

If we consider the current customs and practices of producing scientific knowledge, what can we do in a new journal? What are the conventions we will use 
to define how we present our arguments and express ourselves, which ultimately play a forcefully decisive role in distinguishing the 'publishable' from the 'unpublishable'? Could they be challenging the reproduction of a certain style? It is uncertain whether critical approaches, may they be post-structural, post-colonial or feminist approaches or other anti-positivist traditions, have unsettled the scholarly practice and enabled a break with a positivist rationale of explaining and writing. Many experiments exist, but they are still at the margins. Could we coalesce these margins together and reverse the trend?

This collective article can be read in some ways as an anti-manual with a developed guideline for our future writers, reviewers and readers, inversing many principles taken for granted. Thus, we, purposely, privilege some features which have been rejected by many other journals.

We will keep for example as much as possible an economy of style, which is the one of the mother tongues of the writer, even at the risk (here an opportunity) of creolising a bit the English style. The reason for our opposition to the essay style is therefore not a question of good or bad English as such, but a judgement on what the English language can do with its flexibility and its full dictionary for the social sciences.

We are not saying that a paper does not need to have an argument, but we are aware that to present the argument is not necessarily to project it in the front page. In order to properly justify the originality of the claim, the history of the debate from which the argument has emerged, its complexity, its politics is necessary. Against the false pretense to invent a radically new position or debate, we prefer authors who can trace where they come from. This is of course from an intellectual debate, but also a situated context linked with the social properties of a specific time and milieu.

As Bob Cox said profoundly before it became a mantra without proper analysis, writing to develop a theory is always for someone and for some purpose. ${ }^{26}$ Graham Allison and Murray Edelman insisted also that where you stand depends upon where you sit. We prefer a clear positioning to a pretense of universal claim to an abstract theory detached from the place it comes from. We prefer humble beginners who try to be creative than apprentice philosophers who want to speak in the name of the universal, their nation or their village without having asked anyone what they think. Here is our engagement for what we call an anthropological approach for politics and the international. If explaining this position is lengthy, we will not edit it out, as long as it is helpful in understanding the emergence of the thought. This cannot be relegated into a footnote. The conditions of possibility of an argument are often more

26 Robert W. Cox, "Social Forces, States and World Orders: Beyond International Relations Theory," Millennium 10, no. 2 (1981). 
important than the position itself to understand the validity of the debate and its novelty.

We will also accept long sentences when they are meaningful and nuances and/or control to a certain degree the connotations implied by the denotation of the words. We will recognise this effort to speak a global English, which entails its vernacular role and its pre-eminence, but we do not want to end up with an arbitrary privilege, or, at least, an excessive advantage for those who have English as a mother tongue.

If the article is, for good reasons, more than 12 ooo interesting words, we will certainly not cut it. But we will resist papers where it is obvious that selfindulgence takes privilege over reasoning.

Against this neo liberal tendency of inflation of the self and its own idea of excellence and competition against others, we will encourage even longer articles around 25 to 30000 words written by a proper collective voice as we will explain below.

A publishable article for PARIss will be illustrative of a situation that can be analysed by the description of an analysis of the practical logics at work, implying a reasoning by the author which is not detached from bodies and emotions, and which is not individual but constructed by a set of relations between objective positions in society in which the writer is embedded. The use of metaphors and analogies, using imagination within the reasoning while respecting the validity of truth claims, is often one of the first tools to bring to life and to stimulate a conversation regarding the justifications of forms of power and their (lack of) arbitrariness (or not). So, instead of ending up with a kind of dualist argument between two extremes in order to find the right balance, which is so often the result of the logic of an essay, the article which PARISS will value is open to connections with the humanities, history and anthropology, rather than fascinated with mathematics and physics. Complexity is valuable. Complexity is not a series of complicated facts that can be reduced to simple ones by a step by step reasoning along a main argument, it is a mode of existence in the world, that can be translated only through complex arguments, which may impose a more holistic way of writing, implying dialectical moves with also a strong reflexivity about who is writing, and from what position, in terms of gender, coloniality, class, and ideology, the author is speaking.

Here the great intuitions and propositions of Edgar Morin in his series of books about the contemporary form of knowledge as a method for complex systems, have asked specifically for a style of writing implying a specific typography indicating the (retroactive) feedback loop in a sentence to avoid the linearity of the step by step reasoning. ${ }^{27}$ For him, this was the best way to break 
with the confusion between complicated things which can be broken into simple elements and complex emergences and things which cannot be reduced to elementary "bricks" assembled by one hegemonic logic. He has proposed, with Henri Laborit, that complexity has to be drawn inside the text for generating a reasoning based on a transdisciplinary approach and understood through these symbols of "dialogic loops" destabilizing the "primacy" of a Newtonian physics reasoning. These dialogic loops are the way to building intercommunication between science and philosophy, in which complexity is $c e$ qui est tissé ensemble ${ }^{28}$ (com), dans un enchevêtrement d'entrelacements ${ }^{29}$ (plexus). The writing style in its materiality is therefore an art and a science as such. The style defines the episteme at work and reciprocally. Many people and especially artists have taken this refusal of a causality via our way of reading and have produced collages challenging the idea of a beginning and an end. Morin later tempered his radicality, mainly because of the resistances of the readers and publishers, but he has maintained its exigence on a style which is not linear. We will do the same. Nevertheless, we consider that rupturing the linearity of a style to give its role to diversity, heterogeneities is now a central way of writing and thinking social sciences.

We are keen to have submissions in their original languages and will facilitate the review process in this language, in the same way that the journal International Political Sociology has done in the field of International Relations, paving the way for submissions in Arabic, Portuguese, Farsi and Spanish, among others and facilitating reviews in these languages. Furthermore, translations of these papers into English will take care not to destroy a style specific to different traditions of writing the social sciences but allow instead for more vernacular forms of English. In this vein, the goal of PARISS is to reflect the diversity of styles of writing taking place in order to reinvent academic English in a world of many worlds. We privilege what Blommaert, Jacqumet and Rampton therefore call the "mixedness, creolization, crossover phenomena and heterogeneity" present in a world constituted by transversal lines and hybridities. ${ }^{30}$ In this vein, even the reference style that PARISs prefers is chosen to honor this line of thought; full footnotes, written in the Chicago 17th style are required instead of the usual Harvard style, where disparate authors are often lumped together within the text so as not to take up too much space.

Of course, we do not consider our journal the first to travel in these directions we set out, and owe a debt to some of the wonderful work which has been

28 Translates as "that which is woven together". Authors' translation.

29 Translates as "in an entanglement of intertwining". Authors' translation.

30 Ben Rampton, Crossing: Language and Ethnicity among Adolescents, 3 ed. (Abingdon: Routledge, 2017); Tugba Basaran et al., eds., International Political Sociology: Transversal Lines, Routledge Studies in International Political Sociology (New York: Routledge, 2016). 
undertaken to pluralize the art of writing in global politics, albeit working from the margins. Much of this transdisciplinary dialogue has taken place with the re-emergence of sociological and anthropological interventions into studying 'the international', but this is by no means exhaustive. Jenny Edkins famously called for 'novel writing' within the field of International Relations, ${ }^{31}$ drawing on Elizabeth Dauphinee's pioneering work, The Politics of Exile. ${ }^{32}$ The Journal of Narrative Politics, for example, has emerged from these junctures between narrative, aesthetics, theory and politics, foregrounding autoethnography and storytelling as an art of writing; one way of many through which to navigate the theory-practice relation.

Finally, among the major corrections that we want to introduce, we will verify that it would not be possible for reviewers who disagree with a text to incriminate the style of the author, instead of daring to discuss the content of the contested ideas. Reviewers will be questioned on their own assumptions.

Needless to say that, in that case, the preference or habit for a certain choice of words in the name of purity of the English or about the style of writing encompass a politics, which creates power struggles, dominant positions and symbolic violence which are not recognized as such by the victims of it. Locutors of different languages that use untranslatable terminologies in English or do not privilege the same 'essay style' art of writing, are often disadvantaged if the reviewer interprets their use of particular terminology narrowly, associating it with its specific connotations in English, when the term may in fact have slightly different overtones in other languages. Likewise, if an invention of a specialized terminology which does not emerge from English common sense, is refused on the same bases of "preserving" English from contamination. ${ }^{33}$ The attention also to gendered forms of writing and grammar of language which does not have "neutral" will also be taken into consideration. We will put all our attention to correct these biases, sometimes unconscious, sometimes strategized by a reviewer seeing their role as the one of a gate-keeper.

31 Jenny Edkins, "Novel writing in international relations: Openings for a creative practice," Security Dialogue 44, no. 4 (2013).

32 Elizabeth Dauphinee, The Politics of Exile (London \& New York: Routledge, 2013).

33 To take a famous example the French terminology of surveiller has been translated not as to surveil as it would be incomprehensible with the English connotation, but to discipline, but verbs became nouns essentializing from the very title what Foucault had in mind, and in addition it has created nightmare for further editions when Foucault insisted on the difference between surveiller and discipliner. The refusal to use "dispositive" as it was not in the English dictionary and to use "apparatus" instead has also created many problems for understanding the charge of Foucault against Althusser, as he was using the very same term. A bit of creolization at that time would have helped to clarify theoretical distinctions between the two authors. 
This leads us to a discussion about the reasons we will do the peer-review system differently.

\section{$5 \quad$ Submission Process: Reasons for a Different Peer-review System}

The domination of a certain politics of style and a way of writing would be almost impossible to enforce only by recommendations concerning the guidelines of the journal. So, many social sciences journals are insisting about the role of reviewers who have to discuss the content, but also to police the style. This has certainly a good reason if texts arrive and are not comprehensible, generating nonsense, ${ }^{34}$ but more than often, it gives an exorbitant power to the reviewers who disagree with the content, but dare not to say so in their reviews, and then critique the forms (structure, style, so called clarity of the argument) as a way of dismissing challenging ideas. The review ends up not by describing logical problems and value of the argumentation but turns to "aesthetic" judgements dismissing the constative efforts of "neutrality" to the benefit of their own performatives. Very easily, the process ends via the exclusion of original formulations and ideas, as soon as they do not follow the rules of the essay style. Paradoxically, this is reinforced (and not suppressed) by the fact that the two or three reviewers are fully anonymous, since the anonymity creates an easy way to be dismissive about other ways of presenting argument by just referring to the normal (doxa) as an evidence of the personal judgement.

What is often left unsaid in debates about reviewing is therefore the criteria of anonymity as a condition for fair judgement. Unfortunately, this is not always the case. Anonymity in the form of a double-blind process can certainly be convincing if it is a review process between pairs, and if it effectively delivers fair treatment, instead of just reinforcing the current doxa against innovative ideas and practices. If the proposition of anonymity as a strategy in the hinderance of obsequious clientelism is also important, the need to change the socalled double-bind process is nevertheless urgent for several reasons. First, the pretence that the act of reviewing, as it is today, remains anonymous throughout the entire process is not credible, especially within the digital age. For the reviewer, a quick check about references provided in footnotes correlated with internet searches indicate often if not the name of the person, at least the language s/he knows and the university or country she belongs to. Second, among

34 John Langshaw Austin, How to do things with words (Oxford: Oxford University Press, 1975). 
the bad practices of some reviewers, lay the assumptions that someone who is located outside of the zone of English as a mother tongue is making mistakes and "needs" to be corrected by a "purest" form of writing and that the reviewer is entitled to ask for refusal or major corrections on this basis. This is sometimes awkward for the editor if the reviewer does not realize that the person in question is an anglophone living in a far-away country like Japan, or Netherlands and France, a recurrent point of complaint by editors during discussions. But, this discrimination regarding the style of English has to be taken seriously. It is one of the most effective ways of controlling a journal and framing the boundaries of the authorship by confusing the best ideas and the logic of arguments with a certain style of writing. This implicit colonial take, which is hidden in this move of rejection-discrimination by the style, has to be combatted as well as other forms of discrimination concerning gender, class, nationalities, but is by far less discussed in editorial boards who desire a more equal distribution of articles. A decolonial project, if it goes beyond the most visible reasons, has to address this form of symbolic domination which explains, more than other criteria, the low rate of papers coming from the non-anglophone Global South in top journals of social sciences.

It is also interesting to see the modalities of resistance and strategies of distinction used by some of these anglophones abroad. To be sure to be recognized as "proper" native English locutor, they often quote the most "idiomatic" items (relics, even totems) of an English culture in order to avoid being discriminated on their "level" of English. As we are well aware "ce que parler veut dire" (translated as "In Other Words") cannot be summed up by a perfect grammar and style, providing equality of chances, the use of language and style is a permanent struggle for distinction and signs of age, class or gender recognitions (cf the so-called Queen's English). ${ }^{35}$

It is difficult, even when being aware of these forms of symbolic violence to eliminate them. We suggest nevertheless to alleviate them, at least a bit, by modifying the role of the traditional anonymous peer review system. Concerning this aspect of the form and style of the submission, one of the reviewers will always be chosen from our large scientific committee, and in addition we will ask one (or two) external reviewers to act as experts on the topic. The internal reviewer will be in charge of entering into a productive dialogue with the author in terms of helping them to express their own style and argumentation, whilst keeping a coherent meaning and logical argumentation for the English audience. This internal reviewer will also summarize the views of

35 Pierre Bourdieu, Ce que parler veu dire: L'économie des échanges linguistiques (Paris: Fayard, 1982). 
external reviewers, allowing for a collective discussion with the editors. This means abandoning anonymity during the process if necessary. Some editors and publishers may react negatively, but we contend that this needs to be done. This is a way of altering the author's chances of being published and therefore to enhance the diversity of the authorship.

In a similar vein, we also welcome submissions in original mother tongues different from English, and the review process will be carried out in these languages; the list of languages will depend on the capacities and willingness of a large group of academics to enrol into the scientific committee. The final document, once accepted, will have to be translated by the author, and we cannot, before obtaining specific grants, cover the cost of translation, but we consider it our duty, even if it certainly takes time to make constructive suggestions, to help improve a text which has been conceived in a different language and framed in a different style.

Collective Articles: A Necessity for a Different Art of Writing Social Sciences

A way of breaking down the individualist aesthetics valorizing too much to "attract" the audience via catch phrases and tones of declaring "wars" on their colleagues, by claiming an absolute originality and frontier ideas (that competition for grants recommends) is to privilege on the contrary, effective co-writing and collective articles. This is why PARISs will strongly encourage collective writings. We consider that social sciences authors need, against the permanent illusio of the individual little genius, to work collaboratively and to show it in their publications.

When the group of authors has not just collated short individual pieces together with only a common introduction (like many forums), but has worked together to elaborate the structure, the order of the arguments and the narratives strategies, it changes the nature of the art of writing. So, we claim. Negotiation about wordings have taken place. Reflections about the agreement on the place of disagreements between authors have already obliged clarifying the boundaries of the question and the problematization at work. The process of writing has been by far more discussed than in individual pieces. They are more on the side of "slow food" production than "fast food" blogs and tweets, or individual sensational pieces. But their mode of production in terms of writing may help to have fewer, but better articles. If the topic is not the self-promotion of a "party" line, this art of writing collectively often tames the inflammatory rhetoric of the self, claiming to be the "unique supreme", and gives more ground 
to a common reflection, based on different formulations of the core ideas. ${ }^{36}$ This often gives a more accurate perspective insisting on the different facets to express each idea, and it provides to different readership and specialist of only one discipline, a way to better understand what is at stake. This may look sometimes repetitive and "too long", with circumvolutions, but it is a way of describing and analysing which has its own qualities and is metaphorically the equivalent of a $3 \mathrm{D}$ video in comparison with a $2 \mathrm{D}$ image.

Some may prefer the old individual style and if they have great ideas, they will be always welcome in terms of submission, but we want to definitively give a place in the PARISS journal to strong collective articles which exist sometimes by the sole logic of international grants, but cannot find important places in other journals. We consider this task to publish collective articles as one of the most important goal of PARISS project.

These kinds of articles are central for reframing the boundaries of the types of knowledge that can be called social sciences. In the next issues, we will develop these intimate relations between the art of writing and the knowledge connections which define a fluid space, but having nevertheless boundaries between social sciences, humanities and work of fiction on one side, and on the other side with contemporary hard sciences, both of which have developed more of these collective practices, letting social sciences to be the central place of experiment for those who want to convert universities into a place for profit deriving from individual competitions around diplomas, jobs and grants.

The making of "social science laboratories" to use the formula of Bruno Latour, or the one of "collective intellectuals" to use the one of Pierre Bourdieu is not just a nice add-on. It is absolutely central to produce collective articles as an antidote against the hyper individualization, privatization, commercialization which is at stake in current higher education of the Global North. They can structure stronger solidarities, develop better reflexivity, encourage and become embryonic social movements among their own fields and their capacity to speak to an audience, ready itself to take time for serious analysis, and not quick slogans whose quality is more about sense of humour than veracity.

Collective articles, especially when they come from more than one discipline and try to find transversal, transnational, translinguistic lines will be welcome and we will give them all the necessary place they need to express strong ideas with nuances.

By that, we mean to give a chance for collaborative writing where the singular of the self disappears, and where the collective is not an accumulation of

36 Augusto Roa Bastos and Carlos Pacheco, Yo el Supremo (Caracas: Fundacion Biblioteca Ayacucho, 1986). 
different self(ves) but a work in common with an emerging position. The ownership of the full text under a collective label would be preferable to the socalled collective created by the addition of individual contributions along a traditional division of labour and responsibility.

The collective attribution limits the obvious distinctions of the order by which the presentation organizes age, gender, professional status, or alphabetic order. We will discuss with the group proposing the paper their choice of ordering all the names, and in addition of overcoming some asymetries in power relations, we may propose, if necessary, to have only one nickname for the collective and to have a footnote of the people who have participated in it and are ready to claim it publicly immediately, while others may decide to reclaim their participation later and use a nom de plume inside the collective. ${ }^{37}$ Against the politics of publishing only individual essays with light and brilliant thoughts, we consider that journals of social sciences like PARISs if they want to deconstruct disciplinary boundaries seriously, have to promote this collectivisation as a form of knowledge and an art of writing. The journal will try for each issue to have at least one of these collective articles in addition to the four or five individual articles.

These collective articles are also a way to be reflective of a certain moment of research, before presenting the so-called findings and to propose an ongoing conversation beyond disciplinary boundaries when epistemological and methodological conundrums push to write about the level of agreement on the disagreements which is (un)acceptable.

The more we have an institutionalisation of collaboration between « country » teams, the more we need this reflexivity about methods, but also about he the art of writing which is not dispossessing the non-anglophone of their core reasonings and ways to present them.

By signaling this necessity to change the art of writing social sciences, we want even to go further and break with the reproduction of forms of symbolic violence and linguistic colonialism at work. This will imply being consistent with the current decolonial move affecting the different ways of writing social sciences in English, by accepting and encouraging narratives and forms of thought that both refuse to mimic demonstration, propose creative writings and plural styles and keep a non-fiction way of argumentation.

We want also to clarifiy that a call for connections with humanities, anthropology, history is not a call for a fusion and a claim that regimes of truth are

37 For an example, see the collective Candela in politique de la nuit, Cultures \& Conflits. This is the name chosen by more than 15 people coming from different backgrounds around Lille, based in different research centres (CERAPS, CLERSE, LATTS, TVES). 
unimportant. We follow on that Paul Veyne for whom writing history is not to describe facts but to write a novel, taking nevertheless into consideration that this narrative needs to be definitely a novel based on truth of the archives. ${ }^{38} \mathrm{In}$ social sciences we are also in the same position. We are not publishing novels for entertainment, but we can use a style open to complexity like in some fictions if it is the best way to encompass the human experiences and to express them better than an arid reasoning.

Nevertheless, why would we reject a certain style if the understanding provided is higher than the linear flow of argument and if it may push to change practices of certain actors? If the effective short style is efficient regarding its purpose, we will certainly not reject it, by a reverse discrimination, but for us social science styles exist only through their diversity, through the transversal lines they can open, through the fragments which are non-compatibles with a dominant model, but express a specific universe, or more exactly a pluriverse.

\section{Bibliography}

Abbott, Andrew. The Chaos of Disciplines. Chicago: University of Chicago Press, 2001. Albert, Mathias, David Jacobson, and Yosef Lapid. Identities, Borders, Orders: Rethinking International Relations Theory. Borderlines. Minneapolis: University of Minnesota Press, 2001.

Austin, John Langshaw. How to Do Things with Words. Oxford: Oxford University Press, 1975 .

Baines, Erin. Buried in the heart: Women, complex victimhood and the war in northern Uganda. Cambridge University Press, 2017.

Basaran, Tugba, Didier Bigo, Emmanuel-Pierre Guittet, and R.B.J. Walker, eds. International Political Sociology: Transversal Lines, Routledge Studies in International Political Sociology. New York: Routledge, 2016.

Bernstein, Theodore Menline. The Careful Writer: A Modern Guide to English Usage. New York: The Free Press, 1965.

Blommaert, Jan, ed. Language Ideological Debates Vol. 2. Berlin \& New York: de Gruyter, 1999 .

Borges, Jorge Luis. L'aleph. Paris: Gallimard, 1977.

Bourdieu, Pierre. Ce Que Parler Veu Dire: L'économie Des Échanges Linguistiques. Paris: Fayard, 1982.

38 Paul Veyne, Writing History: Essay on Epistemology (Manchester: Manchester University Press, 1984). 
Bourdieu, Pierre. Homo Academicus. Translated by Peter Collier. Palo Alto: Standford University Press, 1988.

Butler, Paul. Out of Style: Reanimating Stylistic Study in Composition and Rhetoric. Logan: Utah State University Press, 2008.

Coby, Tami. "From the Trenches: Dilemmas of Feminist IR Fieldwork." In Feminist Methodologies for International Relations, edited by Brooke A. Ackerly, Jacqui True and Maria Stern, 153-73. Cambridge: Cambridge University Press, 2006.

Cox, Robert W. "Social Forces, States and World Orders: Beyond International Relations Theory." Millennium 10, no. 2 (1981): 126-55.

Das, Veena. Life and Words: Violence and the Descent into the Ordinary. Berkeley: Univ of California Press, 2006.

Dauphinee, Elizabeth. The Politics of Exile. London \& New York: Routledge, 2013.

Deibert, Ronald. Parchment, Printing, and Hypermedia: Communication and World Order Transformation. New York: Columbia University Press, 2000.

Dusak, Anna, ed. Culture and Styles of Academic Discourse, Berlin. de Gruyter, 1997.

Edkins, Jenny. "Novel Writing in International Relations: Openings for a Creative Practice." Security Dialogue 44, no. 4 (2013): 281-97.

Enloe, Cynthia. Bananas, beaches and bases: Making feminist sense of international politics. Berkeley: Univ of California Press, 1989.

King, Gary, Robert O. Keohane, and Sidney Verba. Designing Social Inquiry: Scientific Inference in Qualitative Research. Princeton: Princeton University Press, 1994.

Kuhn, Michael, and Hebe Vessuri, eds. The Global Social Sciences: Under and Beyond European Universalism. New York: Columbia University Press, 2016.

Kuhn, Michael, and Doris Weidemann, eds. Internationalization of the Social Sciences: Asia - Latin America - Middle East - Africa - Eurasia. Bielefeld: Transcript, 2010.

Ling, Lily HM. Postcolonial international relations: Conquest and desire between Asia and the West. Palgrave, 2002.

Moon, Katharine HS. Sex among allies: Military prostitution in US-Korea relations. Columbia University Press, 1997.

Morin, Edgar. La Nature De La Nature. Paris: Seuil, 1977.

Okamoto, Kazumi. "Internationalization of Japanese Social Sciences: Importing and Exporting Social Science Knowledge." In Internationalization of the Social Sciences: Asia - Latin America - Middle East - Africa - Eurasia, edited by Michael Kuhn and Doris Weidemann, 45-66. Bielefeld: Transcript, 2010.

Orwell, George. "Politics and the English Language." Horizon 13, no. 76 (1946): 252-65.

Rampton, Ben. Crossing: Language and Ethnicity among Adolescents. 3 ed. Abingdon: Routledge, 2017.

Ravecca, Paulo, and Elizabeth Dauphinee. "Narrative and the Possibilities for Scholarship." International Political Sociology 12, no. 2 (2018): 125-138. 
Roa Bastos, Augusto, and Carlos Pacheco. Yo El Supremo. Caracas: Fundacion Biblioteca Ayacucho, 1986.

Shapiro, Michael J. "Metaphor in the Philosophy of the Social Sciences." Cultural Critique, no. 2 (1985): 191-214.

Strunk, William Jr. The Elements of Style. San Diego: Harcourt, 1920.

Strunk, William Jr. The Elements of Style. 2nd ed. New York: Macmillan, 1959.

Sylvester, Christine. Feminist theory and international relations in a postmodern era. Cambridge: Cambridge University Press, 1994.

Veyne, Paul. Writing History: Essay on Epistemology. Manchester: Manchester University Press, 1984.

Wacquant, Loïc J.D. "Towards a Reflexive Sociology: A Workshop with Pierre Bourdieu." Sociological Theory 7 , no. 1 (1989): 26-63.

Waever, Ole. "The Sociology of a Not So International Discipline: American and European Developments in International Relations." International Organization 52, no. 4 (1998): 687-727.

Wallerstein, Immanuel. Open the Social Sciences: Report of the Gulbenkian Commission on the Restructuring of the Social Sciences. Palo Alto: Standford University Press, 1996.

Zinsser, William. On Writing Well: An Informal Guide to Writing Nonfiction. New York: Harber \& Row, 1976.

Zinsser, William. On Writing Well: The Classic Guide to Writing Nonfiction. 9 ed. New York: HarperCollins, 2006. 